\title{
DIFFERENT PATTERN IN THE REPRODUCTIVE SYSTEM AND MATING OF INVADER CRAB CHARYBDIS HELLERII (BRACHYURA: PORTUNIDAE): DOES IT REPRESENTS ADVANTAGE OVER NATIVE SPECIES?
}

\author{
Watanabe, T.T. ${ }^{1,2, *} \&$ Zara, F.J. ${ }^{1}$ \\ ${ }^{1}$ Universidade Estadual Paulista "Júlio de Mesquita Filho", Campus de Jaboticabal, \\ Laboratório de Morfologia de Invertebrados (IML). \\ ${ }^{2}$ Universidade Estadual Paulista "Júlio de Mesquita Filho", Campus de Rio Claro, \\ Programa de Pós-Graduação em Ciências Biológicas (Zoologia). \\ *Corresponding author: timoteotw@gmail.com
}

Biological invasions are an environmental problem around the world since non-native species might affect native populations and community. Charybdis hellerii is one of the most widespread Portunidae in the world. In this study, we present the histochemical and ultrastructural description of the reproductive system and mating behavior of $C$. hellerii. Spermatogenesis and spermiogenesis are similar to other Brachyura. It occurs inside the testis and begins in germinal centers and each lobe has different maturation stage. The testes lobes have openings to seminiferous duct and are filled with acidophilic secretion. The vas deferens is not voluminous and it doesn't have lateral pockets in middle and posterior regions, which is uncommon in Portunidae. The luminal secretion of the vas deferens in C. hellerii is different than normally observed in Portunidae and similar to Majoidea. The muscle wrapping in this region is well-developed, which might participate in sperm transfer. The spermatophores doesn't show wall and the spermatozoids are embedded in secretion rich in acid polysaccharides. Also, they have partial dehiscence in sea water. The sperm plug characteristic of portunid species was not observed in $C$. hellerii seminal receptacle (SR). Spermatophores were not found, only free spermatozoa were observed in the (SR) lumen. This is partially explained by the partial dehiscence in sea water. The SR spermatozoa were found immersed in a glycoprotein secretion consisting of neutral and acid polysaccharides, being the latter compound only found after mating. The SR secretions are produced by dense layer which is a stratified-like epithelium located at the dorsal part of SR. The mating of $C$. hellerii in laboratory occurred with females in intermolt stage. In the presence of the female, the male displays courtship behavior and tries to capture the female. After the capture, the male immediately starts to manipulate the female for the copulatory embrace. The sperm transfer time ranged from one to 5 hours. After the sperm transfer, the male releases the female without guarding. Therefore, the results show that $C$. hellerii has a distinct pattern to seminal fluid production, spermatophore morphology, which explains the absence of sperm plug and spermatophores in the SR. The reproductive system of $C$. hellerii concurs with the mating of females in intermolt stage. These characteristics may proportionate an advantage within the family to establish in non-native areas.

Keywords: seminal fluid, sperm plug, sperm transfer, Thalamitinae. 